\title{
Artigo/Article
}

\section{Estudo radiológico do megacólon em área endêmica de doença de Chagas}

\author{
Radiological study on megacolon cases in an endemic area for Chagas disease
}

Cleudson Castro ${ }^{1}$, Esperanza Bernal Hernandez ${ }^{2}$, Joffre Rezende $e^{3,4}$ e Aluizio Prata ${ }^{5,6}$

\section{RESUMO}

Introdução: Foi realizado estudo radiológico do cólon em pacientes de zona endêmica da doença de Chagas usando-se a técnica do enema opaco simplificado de Ximenes e cols. Métodos: Participaram 291 pacientes, com idade media de 48,8 ( $\pm 12,5)$ anos, sendo 222 soropositivos para doença de Chagas. Fizeram radiografias na posição ântero-posterior, póstero-anterior e perfil lateral esquerdo, que foram analisadas por inspeção visual e medida do maior diâmetro em centímetros do reto e sigmoide. Resultados: À inspeção visual, foi possível diagnosticar megacólon em 14 (6,3\%) pacientes chagásicos. A média do diâmetro da ampola retal dos chagásicos $6,3( \pm 1,0) \mathrm{cm}$ foi semelhante a dos não-chagásicos $6,2( \pm 1,0) \mathrm{cm}$ $(\mathrm{p}=0,391)$ e o diâmetro médio da alça sigmoide dos chagásicos $5( \pm 1,6) \mathrm{cm}$ foi maior que o dos não chagásicos 4,4 $( \pm 0,8) \mathrm{cm},(\mathrm{p}=0,001)$. Conclusões: Excluindo-se os casos de megacólon evidente e de provável megacólon, a população chagásica continuou com o diâmetro médio do sigmoide significantemente maior $(\mathrm{p}=0,003)$ que a não chagásica.

Palavras-chaves: Megacólon chagásico. Doença de Chagas. Medidas do sigmoide.

\begin{abstract}
Introduction: A radiological study on the colon of patients from an endemic Chagas disease zone was conducted using the simplified opaque enema technique of Ximenes et al. Methods: The study involved 291 individuals with a mean age of $48.8( \pm 12.5)$ years-old, of whom 222 were seropositive for Chagas disease. Anteroposterior, posteroanterior and left lateral view radiographs were analyzed by visual inspection and measurement of the largest rectal and sigmoid diameters. Results: From the visual inspection, megacolon was diagnosed in $14(6.3 \%)$ Chagas disease patients. The mean diameter of the rectal ampulla among the Chagas patients was $6.3( \pm 1.0) \mathrm{cm}$, similar to the measurement in non-Chagas individuals: $6.2( \pm 1.0)$ $\mathrm{cm}(\mathrm{p}=0.391)$. The mean sigmoid loop diameter in the Chagas patients was $5( \pm 1.6) \mathrm{cm}$, which was larger than among the non-Chagas individuals: $4.4( \pm 0.8) \mathrm{cm}(\mathrm{p}=0.001)$. Conclusions: excluding the evident and probable megacolon cases, the Chagas disease population continued to present a significantly larger mean sigmoid diameter than that observed among non-Chagas individuals $(\mathrm{p}=0.003)$.
\end{abstract}

Key-words: Chagas megacolon. Chagas disease. Sigmoid measurements.

1. Programa de Pós-Graduação em Medicina Tropical, Núcleo de Medicina Tropical, Universidade de Brasília, Brasília DF. 2. Fundação Hospitalar do Distrito Federal, Brasília, DF. 3. Universidade Federal de Goiás, Goiânia, GO. 4. Professor Honoris Causa, Universidade de Brasília, Brasília, DF. 5. Universidade Federal do Triângulo Mineiro, Uberaba, MG. 6. Professor Emérito, Universidade de Brasília, Brasília, DF.

Endereço para correspondência: Prof. Cleudson Castro. Núcleo de Medicina Tropical/Depto ${ }^{\circ}$ de Clínica Médica/UnB. Caixa Postal 4517, 70904-970 Brasília, DF.

Fax: $55613273-2811$

e-mail: tropical@unb.br

Recebido para publicação em 25/03/2010

Aceito em 13/07/2010

\section{INTRODUÇÃO}

O megacólon era raro e quase desconhecido pelos clínicos brasileiros antes de $1920^{1}$. Tudo indica que os primeiros casos no Brasil foram observados por Neiva e Pena ${ }^{2}$, na viagem empreendida pelo interior do país. Nas décadas de 1930 a 1950, começam os estudos das casuísticas hospitalares de megacólon. Etzel, pesquisando arquivos hospitalares e de clínicas particulares na Cidade de São Paulo, no período de 1920 a 1938, coligiu $626 \operatorname{casos}^{1}$ de megaesôfago e megacólon. Dória e Centola ${ }^{3}$ analisando prontuários de duas instituições em São José do Rio Preto, encontraram 71 casos. Posteriormente, Doria ${ }^{4}$ refere que o megacólon é frequente na região de Araraquara. Raia e Campos ${ }^{5}$ fazendo estudo sobre o megacólon, revisaram prontuários do Hospital das Clínicas de São Paulo de abril de 1944 a agosto de 1952 e encontraram 252 casos. Freitas Junior ${ }^{6}$, revendo prontuários do Serviço de Saúde de Uberaba, no período de 1939 a 1950, encontrou 182 casos. Rezende ${ }^{7}$ em Goiânia, afirmava que as intervenções cirúrgicas para megacólon superavam todas as demais para outras afecções do cólon e, mais tarde, relata 622 casos $^{8}$. No período de 1970 a 1978, Raia e Habr-Gama9 ${ }^{9}$, estudando prontuários no Hospital das Clínicas da Universidade de São Paulo, encontraram 344 casos. Por fim, Pinotti ${ }^{10}$ estima que, no Brasil, teríamos aproximadamente 240.000 portadores de megacólon.

Sabe-se que as estatísticas hospitalares, as instituições de referência e os especialistas superestimam as doenças que estudam. Para avaliar melhor a prevalência do megacólon chagásico, o ideal seria realizar estudos na área rural endêmica, o que nem sempre é factível. Como bem expressou Pinotti ${ }^{10}$, é difícil implantar um programa para conhecer a prevalência do megacólon chagásico porque o enema opaco é incômodo. É necessário pensar em métodos mais simples, possíveis de serem aplicados nas áreas endêmicas do interior do país. Os estudos de campo sobre megacólon talvez tenham sido feitos primeiro por Macêdo ${ }^{11}$, em são Felipe, que levou em consideração o critério do paciente apresentar constipação intestinal até de 
oito dias, ou ter fecaloma. Dias ${ }^{12}$, estudando pacientes crônicos de Bambuí, com antecedentes de fase aguda, observou $28,7 \%$ de megacólon entre os que tinham período agudo conhecido e $16,9 \%$ entre aqueles cuja data da fase aguda era desconhecida. Já Faria ${ }^{13}$, realizando o enema opaco em 47 chagásicos de área endêmica, encontrou apenas um $(2,1 \%)$ caso de megacólon e Pompeu ${ }^{14}$, nessa mesma área, nove anos mais tarde, realizou enema opaco em 59 chagásicos, encontrando uma prevalência de 3,4\%.

Como se pode observar, os poucos estudos sobre megacólon em áreas endêmicas basearam-se em critérios clínicos ${ }^{11,15}$; ou critérios clínicos e radiológicos ${ }^{12}$. Apenas Faria ${ }^{13}$ e Pompeu ${ }^{14}$ fizeram estudo de campo baseado no enema opaco. Como é compreensível, o enema opaco clássico é difícil de ser realizado nas pequenas cidades, por falta de aparelho de raios-X e da aquiescência dos pacientes. Ciente dessas dificuldades, Ximenes e cols ${ }^{16}$ idealizaram um método de enema opaco simples, que dispensa o preparo prévio e o duplo contraste pela introdução de ar no cólon. Este método, aplicado em área endêmica do interior do país, facilitaria o estudo da prevalência do megacólon e este foi o objetivo desse trabalho.

\section{MÉTODOS}

O estudo radiológico do cólon foi realizado entre maio de 2000 e agosto de 2001, em pacientes do Projeto Mambaí, onde 34,4\% da população eram soropositivas para doença de Chagas. Foi utilizada a técnica do enema opaco preconizado por Ximenes e cols ${ }^{16}$, com algumas modificações. O exame foi realizado no Município de Damianópolis, cidade a $18 \mathrm{~km}$ da sede de Mambaí. Um técnico de radiologia, com experiência em enema opaco, veio de Brasília treinar o técnico do hospital local, realizando juntos os primeiros exames. Um pesquisador em Brasília listou os indivíduos do projeto, que deviam fazer o exame e entregou ao médico que dirigia os trabalhos na área. Este desconhecia o estado clínico e sorológico dos pacientes. Foram incluídos no estudo adultos com seis reações sorológicas positivas para doença de Chagas, e que tinham a forma indeterminada, cardíaca ou digestiva da doença, e indivíduos com seis reações negativas com sintoma de obstipação. Foram excluídos pacientes com cardiopatia grave e gestantes. A localização dos indivíduos coube a um guarda sanitário, morador no município e atuante no projeto desde 1975 , que sabia onde encontrá-los. Um motorista transportou os pacientes para o Município de Damianópolis e, em média, foram examinadas seis pessoas por dia. Ao chegar ao hospital, o paciente respondia a um questionário dirigido, previamente elaborado, contendo dados de identificação, sexo, idade e sintoma de obstipação.

$\mathrm{Na}$ sala de radiologia, usando um chambre, os pacientes foram posicionados em decúbito dorsal na mesa de exame e realizada uma radiografia simples do abdome para descartar eventual presença de fecaloma. Poucos minutos antes do exame foi preparada a suspensão de $150 \mathrm{ml}$ de sulfato de bário em $1.000 \mathrm{ml}$ de água. O enema foi aplicado lentamente com o paciente em decúbito lateral esquerdo estando o recipiente com o meio de contraste a $1,5 \mathrm{~m}$ acima do plano da mesa de exame. Foram feitas três radiografias nas projeções, ântero-posterior, póstero-anterior e lateral esquerda, com 80 a 100 kilovolts e 0,30 a 0,40 miliamperes (mAs), nos decúbitos ântero-posterior e póstero-anterior e 1 a $1,2 \mathrm{mAs}$ na projeção de perfil. A revelação dos filmes foi feita logo após o exame. O tempo utilizado para um exame, desde o questionário até a realização das radiografias, foi de aproximadamente 40 minutos. As radiografias foram levadas para Goiânia e interpretadas por um dos autores (JR), que desconhecia os dados dos pacientes. A interpretação foi feita pela observação visual e pela medida do reto e sigmoide nos filmes analisados ao negatoscópio. Foi medido o maior diâmetro da ampola retal em centímetros $(\mathrm{cm})$ na projeção de perfil e o maior diâmetro da alça sigmoide na projeção ântero-posterior ou, quando foi impossível a medida nessa projeção, usou-se a póstero-anterior.

\section{Análise estatística}

Todas as informações foram arquivadas em um banco de dados. Os dados foram analisados com o auxílio do programa SPSS 9.0 para Windows. Para todos os testes utilizados, foi fixado um limite de significância de 0.05 . Foram utilizados os testes de Student e o exato de Fisher para determinar a significância das diferenças encontradas nas médias das variáveis quantitativas.

\section{Ética}

A população dessa área vem realizando exames desde 1974. Esse projeto foi aprovado pelo Comitê de Ética da Faculdade de Ciências da Saúde da Universidade de Brasília (UnB) e conduzida segundo as normas da resolução 196/96. Foi explicado a cada paciente o objetivo do trabalho e o tipo de exame que seria feito. Foi pedido o consentimento por escrito, e só depois de obtido o estudo foi realizado. Os pacientes que precisaram tratamento especializado foram encaminhados ao Hospital Universitário de Brasília. Durante o período do estudo, a população foi atendida no posto médico de Mambaí, mantido pela UnB.

\section{RESULTADOS}

Foram estudados radiologicamente 303 indivíduos do projeto Mambaí, mas 12 foram excluídos, quatro por não terem exames sorológicos, dois que tinham sorologia duvidosa e seis nos quais não foi possível obter as medidas pretendidas. Foram avaliados, portanto, 291 pacientes, dos quais 222 eram soropositivos para doença de Chagas. A idade variou de 27 a 87 anos, sendo a idade média da população examinada de $48,8( \pm 12,5)$ e dos soropositivos para doença de Chagas 49,1 $( \pm 12,4)$ anos.

A leitura das radiografias foi realizada por um dos autores (JR) que desconhecia a sorologia dos pacientes e que, à simples inspeção visual, fez o diagnóstico de megacólon em 14 casos, assim distribuídos: megassigmoide, 12 casos, megassigmoide distal e megarreto, um caso e megarreto isolado, um caso. Todos os 14 com megacólon foram soropositivos. Ainda à simples inspeção visual das radiografias levantou-se a probabilidade de megacólon em oito casos, assim distribuídos: megassigmoide, cinco casos, e megarreto três casos. Dos oito, seis foram soropositivos e dois soronegativos. Nos demais, a observação visual das radiografias não despertou a atenção do especialista. Além da análise visual, procedeu-se à medida transversal em centímetros, do maior diâmetro do reto e do sigmoide.

De cada paciente, foi medido o diâmetro do reto na radiografia de perfil, colhida em decúbito lateral esquerdo. Dos radiografados, 291 apresentaram exames que possibilitaram medir o diâmetro do reto, dos quais, 222 eram soropositivos e 69 soronegativos. A análise das medidas mostrou que o diâmetro médio do reto dos pacientes com infecção chagásica foi de $6,3( \pm 1,0) \mathrm{cm}$ e não diferiu da média dos pacientes sem doença de Chagas $6,2( \pm 1,0) \mathrm{cm},(\mathrm{p}=0,391)$, conforme se observa na Tabela 1. Quando se considerou o diâmetro médio do reto somente dos pacientes do sexo feminino, não se observou diferença estatística significante $(\mathrm{p}=0,813)$, entre portadores ou não 
TABELA 1 - Diâmetro médio do reto em centímetros de pacientes com e sem infecção chagásica.

\begin{tabular}{|c|c|c|c|c|c|c|c|c|}
\hline \multirow[b]{2}{*}{ Diâmetro médio } & \multicolumn{3}{|c|}{ Chagásicos } & \multicolumn{3}{|c|}{ Não chagásicos } & \multirow[b]{2}{*}{$t$} & \multirow[b]{2}{*}{$\mathrm{p}$} \\
\hline & $\mathrm{n}^{\mathrm{o}}$ & diâ & ep & $\mathrm{n}^{\mathrm{o}}$ & diâ & ep & & \\
\hline População examinada & 222 & 6,3 & 1,0 & 69 & 6,2 & 1,0 & 0,859 & 0,391 \\
\hline feminino & 127 & 6,2 & 1,1 & 47 & 6,2 & 1,0 & 0,237 & 0,813 \\
\hline masculino & 95 & 6,5 & 0,9 & 22 & 6,3 & 1,0 & 0,878 & 0,382 \\
\hline sem megacólon & 208 & 6,3 & 1,0 & 69 & 6,2 & 1,0 & 0,478 & 0,633 \\
\hline sem megacólon e suspeitos & 202 & 6,2 & 1,0 & 67 & 6,2 & 1,0 & 0,403 & 0,688 \\
\hline com megacólon & 14 & 7,2 & 1,8 & - & - & - & - & \\
\hline suspeitos de megacólon & 6 & 7,7 & 1,1 & 2 & 7,2 & 1,8 & 0,428 & 0,683 \\
\hline
\end{tabular}

no: número de pacientes, diâ: diâmetro, ep: erro padrão, t: teste de Student, p: probabilidade.

da infecção chagásica, o mesmo ocorrendo com os pacientes do sexo masculino $(\mathrm{p}=0,382)$ (Tabela $\mathbf{1})$.

De modo semelhante ao que ocorreu com o reto, foi realizada a medição do maior diâmetro do sigmoide, preferencialmente na radiografia em decúbito ântero-posterior. Dos radiografados, foi possível medir o diâmetro do sigmoide de 290, dos quais 221 soropositivos e 69 soronegativos. Quando se analisaram as medidas dos pacientes chagásicos, obteve-se um diâmetro médio de $5( \pm 1,6)$ $\mathrm{cm}$, significativamente maior que aquele de 69 pacientes sem doença de Chagas 4,4 $( \pm 0,8) \mathrm{cm}(\mathrm{p}=0,001)$ como se observa na Tabela 2. Quando se considerou somente os indivíduos do sexo feminino, verificou-se que o diâmetro médio do sigmoide de 127 chagásicos foi maior que o dos 47 não-chagásicos $(\mathrm{p}=0,013)$, conforme mostra a Tabela 2. Análise semelhante com a população masculina mostrou tendência dos chagásicos a terem maior diâmetro médio do sigmoide em relação aos não-chagásicos, $(\mathrm{p}=0,058)$ (Tabela 2).

Considerando a população masculina examinada, verificouse que o diâmetro médio do reto $6,5( \pm 1,0) \mathrm{cm}$ e do sigmoide $5,1( \pm 1,7) \mathrm{cm}$ foi, respectivamente, maior e significante $(\mathrm{p}=0,042$ e 0,029 ) em relação ao sexo oposto (Tabela 3 ).

TABELA 2 - Diâmetro médio do sigmoide em centímetros de pacientes com e sem infecção chagásica.

\begin{tabular}{|c|c|c|c|c|c|c|c|c|}
\hline \multirow[b]{2}{*}{ Diâmetro médio } & \multicolumn{3}{|c|}{ Chagásicos } & \multicolumn{3}{|c|}{ Não chagásicos } & & \multirow[b]{2}{*}{$\mathrm{p}$} \\
\hline & $\mathrm{n}^{\mathrm{o}}$ & diâ & ep & $\mathrm{n}^{\mathrm{o}}$ & diâ & ep & & \\
\hline População examinada & 221 & 5,0 & 1,6 & 69 & 4,4 & 0,8 & 3,26 & 0,001 \\
\hline feminino & 127 & 4,8 & 1,3 & 47 & 4,3 & 0,8 & 2,519 & 0,013 \\
\hline masculino & 94 & 5,2 & 1,8 & 22 & 4,5 & 0,7 & 1,914 & 0,058 \\
\hline sem megacólon & 207 & 4,7 & 0,8 & 69 & 4,4 & 0,8 & 2,899 & 0,004 \\
\hline sem megacólon e suspeitos & 201 & 4,7 & 0,8 & 67 & 4,3 & 0,7 & 3,028 & 0,003 \\
\hline com megacólon & 14 & 9,6 & 2,6 & - & - & - & - & \\
\hline suspeitos de megacólon & 6 & 6,2 & 1,0 & 2 & 5,8 & 1,6 & 0,396 & 0,706 \\
\hline
\end{tabular}

no: número de pacientes, diâ: diâmetro, ep: erro padrão, t: teste de Student, p: probabilidade.

TABELA 3 - Diâmetro médio em centímetros, do reto e sigmoide, segundo o sexo.

\begin{tabular}{|c|c|c|c|c|c|c|c|c|}
\hline \multirow[b]{2}{*}{ Diâmetro médio } & \multicolumn{3}{|c|}{ Masculino } & \multicolumn{3}{|c|}{ Feminino } & \multirow[b]{2}{*}{$\mathrm{t}$} & \multirow[b]{2}{*}{$\mathrm{p}$} \\
\hline & $\mathrm{n}^{\mathrm{o}}$ & diâ & ep & $\mathrm{n}^{\mathrm{o}}$ & diâ & ep & & \\
\hline Ampola retal & 117 & 6,5 & 1,0 & 174 & 6,2 & 1,1 & 2,048 & 0,042 \\
\hline Alça sigmoide & 116 & 5,1 & 1,7 & 174 & 4,7 & 1,2 & 2,192 & 0,029 \\
\hline
\end{tabular}

Se dos 290 pacientes em que se fez a medição do sigmoide, forem excluídos os 14 com megacólon evidente à inspeção e empreendida nova análise dos dados, verifica-se que o diâmetro médio do sigmoide dos 207 portadores com infecção chagásica continua maior e significante em relação aos 69 não-infectados, conforme se vê na Tabela 2. Ainda mais, se forem subtraídos os que tinham megacólon à inspeção e também os suspeitos de megacólon, somando 22 pacientes, ao procederse à análise, verifica-se que o diâmetro médio do sigmoide dos 201 chagásicos remanescentes permanece maior e significante em relação aos 67 pacientes soronegativos, conforme demonstra a Tabela 2.

Os 14 pacientes que tinham megacólon evidente eram chagásicos e apresentaram o diâmetro médio do reto e sigmoide de 7,2 $( \pm 1,8)$ e $9,6( \pm 2,6) \mathrm{cm}$, respectivamente, bem acima do diâmetro médio da população examinada que tinha infecção chagásica (Tabelas 1 e 2). Em 11 dos 14, foi medido o comprimento do sigmoide; cinco tinham $70 \mathrm{~cm}$ ou mais, caracterizando o dolicomegacolon. Na Tabela 4, podem ser vistos os 14 pacientes, distribuídos conforme a faixa etária, sendo que 4 (28,6\%) tinham, à época do exame, entre 36 e 39 anos, isto é, eram relativamente jovens para serem portadores desse tipo de afecção. $\mathrm{Na}$ Tabela 4, se considerarmos somente as faixas de 30-39 e 70-79 anos, a prevalência (oculta) seria 6,7\% (4/60) e 13,3\% (2/15), respectivamente, e no interregno $9,4 \%(5 / 53)$, portanto houve incremento do megacólon com os anos, mas não sistemático em todas as faixas etárias. $\mathrm{Na}$ população com infecção chagásica, o maior diâmetro do reto, foi $11,5 \mathrm{~cm}$ e do sigmoide $17,4 \mathrm{~cm}$, enquanto na população não chagásica o maior diâmetro do reto foi $8,5 \mathrm{~cm}$ e do sigmoide $7 \mathrm{~cm}$. Houve maior número de pacientes com comprometimento do sigmoide que do reto e dos oito suspeitos de megacólon seis foram soropositivos.

TABELA 4 - Distribuição de 14 indivíduos com megacólon chagásico segundo a faixa etária.

\begin{tabular}{lccc}
\hline Faixa etária & Pacientes & Megacólon & Porcentagem \\
\hline $27-39$ & 62 & 4 & 6,4 \\
$40-49$ & 57 & 2 & 3,5 \\
$50-59$ & 53 & 5 & 9,4 \\
$60-69$ & 33 & 1 & 3,0 \\
$70-87$ & 17 & 2 & 11,8 \\
\hline Total & $\mathbf{2 2 2}$ & $\mathbf{1 4}$ & $\mathbf{6 , 3}$ \\
\hline
\end{tabular}

A prevalência de megacólon, avaliada pela inspeção das radiografias foi 6,3\% (14/222). A suspeita de megacólon à inspeção foi de 2,7\% (6/222) entre os chagásicos e 2,9\% (2/69) entre os não chagásicos. Em seis pacientes não foi possível medir o diâmetro do reto; três eram soropositivos e três soronegativos. De modo semelhante, em sete não foi possível medir o diâmetro do sigmoide; quatro foram soropositivos e três soronegativos.

Um paciente com infecção chagásica, há anos operado de megacólon, e ultimamente submetido ao clister opaco, mostrou-se absolutamente normal, e não chamou a atenção do examinador das radiografias; apresentou diâmetro do reto e sigmoide de $5,8 \mathrm{~cm}$ e $4,1 \mathrm{~cm}$, respectivamente, medidas abaixo do diâmetro médio apresentado pela população chagásica examinada.

\section{DISCUSSÃO}

A avaliação radiológica do cólon teve como objetivo determinar a prevalência de megacólon em área rural onde a doença de Chagas é endêmica. Em 2002, foram publicados dados sumários sobre esta investigação ${ }^{17}$, ampliam-se agora informações mais detalhadas e 
completas susceptíveis de serem melhor avaliadas. Acrescenta-se que estudo similar, ainda que sumário, foi realizado em 2004 em Belo Horizonte ${ }^{18}$. Foi observado que a prevalência de megacólon chagásico em Mambaí foi pouco menor que a de megaesôfago calculada em 1975. Foi encontrado megacólon em 6,3\% dos chagásicos examinados. Esse exame foi realizado após mais de 25 anos de seguimento da população, isto é, houve tempo suficiente para desenvolver megacólon nesse período. Em épocas anteriores, nessa área, o diagnóstico presuntivo era feito conforme o número de dias de obstipação. Nos últimos 40 anos, o diagnóstico tem-se fundamentado em observações clinicas. Assim, Macedo ${ }^{11}$ encontrou uma prevalência de megacólon de 1,8\%, Castro ${ }^{15}$ observou 4,8\% em Mambaí e em 1995 encontrou 9,5\% na mesma área ${ }^{19}$. Faria ${ }^{13}$, no Município de Luz, Estado de Minas Gerais, aplicando o enema convencional, relatou apenas 2,1\% de megacólon e, na mesma população 10 anos após, Pompeu ${ }^{14}$ encontrou $3,4 \%$ com a mesma técnica radiológica. Cunha e $\operatorname{cols}^{20}$, realizando o enema opaco clássico em doadores de sangue observaram que 6,5\% tinham megacólon chagásico.

O estudo da forma digestiva da doença de Chagas na população tem sido difícil nas áreas rurais. Mesmo nos dias atuais há muita dificuldade para realizar-se enema opaco na área rural, porque embora exista energia elétrica em quase todo o interior do país, faltam aparelhos de raios-X. Em reunião promovida pelo $\mathrm{CNPq}$ em 1974, sobre metodologia de estudos longitudinais, foi recomendado que para o diagnóstico da forma digestiva era importante a avaliação clínica e o exame radiológico. Em relação ao megacólon, indicavam-se como sintomas principais a obstipação, meteorismo e a presença de fecaloma. O documento da reunião destacou que o exame radiológico do cólon deveria ser feito em ambiente hospitalar ${ }^{21}$, e até hoje, decorridos mais de 35 anos, apesar do grande desenvolvimento alcançado pelo Brasil, o estudo radiológico do cólon na área rural tem sido precário. Em geral, o megacólon tem sido considerado do ponto de vista clinico usando como parâmetro, principalmente a presença de obstipação acima de sete dias.

Os investigadores têm tido dificuldade em classificar os indivíduos na forma indeterminada da doença de Chagas, pela falta de acesso a métodos diagnósticos para exploração do cólon. Daí, boa parte dos estudos considerarem a obstipação pertinaz como indicativo de megacólon. Atualmente, o exame mais apropriado para diagnosticar o megacólon chagásico é o enema opaco. Ainda não existe um padrão radiológico do que é normal e anormal em relação a colopatia chagásica. Recentemente, Silva e cols ${ }^{22}$ propuseram uma classificação radiológica do megacólon chagásico, após análise no negatoscópio medindo o eixo transverso da alça sigmoide de 135 enemas opacos (76 de chagásicos com megacólon e 59 não chagásicos). Propuseram a seguinte classificação, grau zero: eixo transverso de 2 a $5 \mathrm{~cm}$ inclusive, e os pacientes com essas medidas foram não chagásicos; grau 1: consistiu na interseção entre o normal e patológico, o eixo mediu 5 a $9 \mathrm{~cm}$ inclusive, $76 \%$ dos pacientes foram chagásicos e 24\% não chagásicos; grau 2: eixo transverso de 9 a $13 \mathrm{~cm}$ inclusive; e grau 3: mais de $13 \mathrm{~cm}$; nesses dois últimos grupos todos foram chagásicos. Concluindo, classificaram o megacólon chagásico em graus 1, 2 e 3 de acordo com as medidas acima mencionadas. A anatomia comparada mostra que as medidas do trato digestivo estão estreitamente relacionadas com hábitos alimentares ${ }^{23}$. Os carnívoros têm intestino mais curto que os herbívoros. Na cordilheira da América do Sul, acima dos $3.000 \mathrm{~m}$, existe o dolicomegacólon andino que os pesquisadores atribuem em parte à alimentação rica em vegetais. Nessa condição, à semelhança do megacólon chagásico, há dilatação e alongamento do cólon ${ }^{24,25}$.
Os principais problemas para o diagnóstico radiológico do cólon na população rural de área endêmica são a falta de aparelhagem e a pouca aceitação do enema. Os estudos de prevalência de megacólon têm sido realizados em ambientes hospitalares, o que pode levar a resultados tendenciosos. Ximenes e $\operatorname{cols}^{16}$ introduziram uma técnica radiológica que facilitou esse estudo na área rural, dispensando o preparo do cólon e prescindindo da injeção de ar que são incômodos.

No presente estudo, mostrou-se que o método de Ximenes e cols ${ }^{16}$ foi factível, adotando-se algumas modificações que diminuíram custo sem perda da qualidade das radiografias. $\mathrm{O}$ irrigador foi colocado a 1,5m acima do plano da mesa de raios-X, em lugar de 1,0m da técnica original, o que facilitou a aplicação do enema e diminuiu o risco de precipitação do bário. Em vez de $300 \mathrm{ml}$ de sulfato de bário usou-se $150 \mathrm{ml}$ diluídos até o volume de $1.150 \mathrm{ml}$. Não houve recusa por parte dos pacientes e nenhuma complicação devida ao exame.

O diagnóstico de megacólon por enema opaco pode ser feito à inspeção visual da radiografia quando a dilatação é expressiva, porém nos casos limítrofes o diagnóstico à simples vista deixa dúvidas. Nesses casos, a medida do sigmoide contrastado está indicada. Viu-se que o diâmetro médio do sigmoide nos chagásicos foi significativamente maior que o dos não chagásicos. O diâmetro médio do sigmoide dos pacientes com megacólon foi muito superior ao da população chagásica e mais que o dobro da população não chagásica, o que impressiona à primeira vista, tornando o diagnóstico óbvio. Por outro lado, quando se compara o diâmetro médio do sigmoide dos chagásicos com provável megacólon, com o da população chagásica examinada, a diferença foi bem menor, trazendo dúvida à observação visual. Em relação ao reto, o diâmetro médio encontrado na população chagásica foi semelhante ao da população não chagásica.

Podemos concluir que o diâmetro médio do sigmoide da população chagásica examinada foi menor que o daqueles com suspeita de megacólon, que, por sua vez, foi menor que aqueles com megacólon evidente à inspeção.

Este trabalho foi feito pela mesma equipe, portanto a metodologia foi uniforme durante todo o seu transcurso. A análise dos dados clínicos e complementares, como a presença ou não de obstipação, a sorologia para doença de Chagas, inspeção visual da radiografia e medida do maior diâmetro do sigmoide contrastado, podem auxiliar na definição entre o cólon normal e megacólon.

Há necessidade de estudo radiológico, em área endêmica, do cólon dos indivíduos classificados na forma indeterminada da doença de Chagas, já que esse estudo constatou casos de megacólon em indivíduos previamente insuspeitos.

A realização deste estudo evidenciou a existência de colopatia em indivíduos chagásicos oligo ou assintomáticos, e mostrou que o enema opaco simplificado pode ser realizado nas áreas endêmicas de doença de Chagas para estudo do cólon. Finalmente, permitiu determinar o padrão de medidas na população de Mambaí isenta de infecção chagásica, que, a propósito, tem o diâmetro transverso do reto e sigmoide maiores que o encontrado em Uberaba, no Triângulo Mineiro ${ }^{26}$.

\section{CONFLITO DE INTERESSE}

Os autores declaram não haver nenhum tipo de conflito de interesse no desenvolvimento do estudo. 


\section{REFERÊNCIAS}

1. Etzel E. Distribuição geográfica do megaesôfago-megacolon. Estudo atual da teoria etiológica da avitaminose B1. Estudo de 626 casos. Rev Assoc Paulista Med 1939; 15:103-158.

2. Neiva A, Penna B. Viagem científica pelo norte da Bahia, sudoeste de Pernambuco, sul do Piauhi e de norte a sul de Goiáz. Mem Inst Oswaldo Cruz 1916; Tomo III fasc 3:75-224.

3. Doria OBS, Centola C. Tratamento do megacólon. Rev Bras Gastroenterol $1950 ; 2: 131-172$.

4. Doria OBS. Conduta na oclusão aguda do megacólon. Rev Bras Gastroenterol 1953; 5:379-392.

5. Raia AA, Campos OM. Megacolo - contribuição ao estudo de sua patogenia e tratamento. Rev Med Cir Sao Paulo 1955; 15:391-442.

6. Freitas-Jr SV. Megacólon e megaesôfago no Brasil Central. Resen Clin Cient 1950; 19:411-423.

7. Rezende JM. Evolução dos conhecimentos sobre os megas. Rev Gastroenterol Nordeste 1964; 3:23-52.

8. Rezende JM. Chagasic mega syndromes and regional differences. In: American Trypanosomiases Research. Pan American Health Organization. Scientific Publication n. ${ }^{\circ}$ 318; 1975. p. 195-205.

9. Raia AA, Habr-Gama A. Megacólon. In: Raia AA, editor. Manifestações digestivas da moléstia de Chagas. São Paulo: Sarvier; 1983. p. 207-216.

10. Pinotti HW. Aspectos sócio econômicos do megaesôfago e megacólon. In: Raia AA, editor. Manifestações digestivas da Moléstia de Chagas. São Paulo: Sarvier; 1983. p. 21-24.

11. Macêdo V. Influência da exposição à reinfecção na evolução da doença de Chagas. Rev Pat Trop 1976; 5:33-116.

12. Dias JCP. Doença de Chagas em Bambuí Minas Gerais, Brasil. Estudo clínico epidemiológico a partir da fase aguda, entre 1940 e 1982. [Tese de Doutorado]. [Belo Horizonte]: Universidade Federal de Minas Gerais; 1982.

13. Faria CA. Condições de saúde e doença de trabalhadores rurais do município de Luz MG, com especial atenção a prevalência e morbidade da moléstia de Chagas. [Tese de Doutorado]. [Belo Horizonte]: Universidade Federal de Minas Gerais; 1978.

14. Pompeu FR. Estudo longitudinal da doença de Chagas em trabalhadores rurais do Município de Luz MG (1976 - 1985). [Dissertação de Mestrado]. [Belo Horizonte]: Universidade Federal de Minas Gerais; 1990.

15. Castro C. Influência da parasitemia no quadro clínico da doença de Chagas. Rev Pat Trop 1980; 9:73-136.

16. Ximenes CA, Rezende JM, Moreira H, Vaz MGM. Técnica simplificada para diagnóstico radiológico do megacólon chagásico. Rev Soc Bras Med Trop 1984; 17 (supl):23.

17. Hernandez EB, Rezende JM, Macêdo V, Castro CN. Estudo radiológico do cólon em indivíduos de área endêmica de doença de Chagas através da técnica simplificada de Ximenes. Rev Soc Bras Med Trop 2002; 35(supl III):188-189.

18. Simões AA, Jannuzzi JH, Valadares AT, Magalhães JP, Figueredo MT, Gontijo ED. Estudo comparativo clínico-radiológico do enema opaco em pacientes portadores de doença de Chagas. Rev Soc Bras Med Trop 2004; 37(supl III):21.

19. Castro C. Estudo longitudinal da parasitemia na doença de Chagas e sua correlação com a evolução clínica. [Tese de doutorado]. [Belo Horizonte]: Universidade Federal de Minas Gerais; 1993.

20. Cunha TC, Souto PE, Bonini N, Pachaly RM, Spiazzi MA, Dalla DM. Megaesôfago, megacólon e alterações eletrocardiográficas em candidatos a doadores de sangue com reações sorológicas positivas para doença de Chagas, no município de Santa Maria, Rio Grande do Sul. Rev Goiana Med 1987; 33:17-24.

21. Conselho Nacional de Pesquisa. Epidemiologia da doença de Chagas. Objetivos e metodologia dos estudos longitudinais. Relatório técnico número 1, Rio de Janeiro; 1974.

22. Silva AL, Giacomin RT, Qujirino VA, Miranda ES. Proposta de classificação do megacólon chagásico através do enema opaco. Rev Col Bras Cir 2003; 30:4-10.

23. Franco FE. El colon íleo-pelvico em los peruanos. [Tese de Doutorado]. [Lima]: Universidad Nacional Mayor de San Marcos; 1965.
24. Adad SJ, Laguna-Torres VA, Arrieta EG, Prata A. Estudo preliminar comparativo anátomo-patológico entre megacólon andino e megacólon chagásico. Rev Soc Bras Med Trop 2002; 35(supl III): 194.

25. Frisancho D, Frisancho O. Dólicomegacolon Andino y megacolon chagásico: sus características y diferencias. Rev Gastroenterol Peru 1985; 5:81-87.

26. Lopes GP, Torres VAL, Ramos A, Prata A. Enema opaco do reto-sigmoide em pacientes não chagásicos de Uberaba (MG) e Puno. Rev Soc Bras Med Trop 2002; 35(supl III):204-205. 